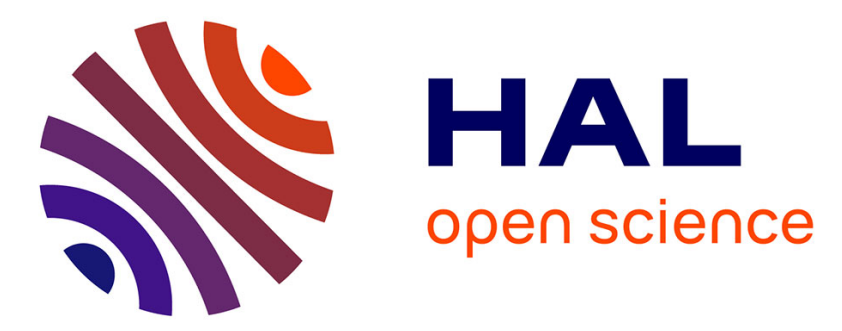

\title{
THEORY OF LASER-ENHANCED IONIZATION IN FLAMES - COMPARISON WITH EXPERIMENTS
}

\author{
O. Axner, T. Berglind, J. Heully, I. Lindgren, H. Rubinsztein-Dunlop
}

\section{To cite this version:}

O. Axner, T. Berglind, J. Heully, I. Lindgren, H. Rubinsztein-Dunlop. THEORY OF LASERENHANCED IONIZATION IN FLAMES - COMPARISON WITH EXPERIMENTS. Journal de Physique Colloques, 1983, 44 (C7), pp.C7-311-C7-317. 10.1051/jphyscol:1983728 . jpa-00223285

\section{HAL Id: jpa-00223285 https://hal.science/jpa-00223285}

Submitted on 1 Jan 1983

HAL is a multi-disciplinary open access archive for the deposit and dissemination of scientific research documents, whether they are published or not. The documents may come from teaching and research institutions in France or abroad, or from public or private research centers.
L'archive ouverte pluridisciplinaire HAL, est destinée au dépôt et à la diffusion de documents scientifiques de niveau recherche, publiés ou non, émanant des établissements d'enseignement et de recherche français ou étrangers, des laboratoires publics ou privés. 


\title{
THEORY OF LASER-ENHANCED IONIZATION IN FLAMES - COMPARISON WITH EXPERIMENTS
}

\begin{abstract}
O. Axner, T. Berglind, J.L. Heully, I. Lindgren and H. Rubinsztein-Dunlop
Department of Physics, Chalmers University of Technology, S-412 96 Göteborg, Sweden
\end{abstract}

Résumé - La spectroscopie optogalvanique ou par augmentation de l'ionisation à l'aide d'un laser (L.E.I.) a été mise en ceuvre pour la détection d'éléments à l'état de traces dans une flamme par excitation à un et deux échelons. La sensibilité, définie comme étant le signal L.E.I. divisé par I'énergie de l'impulsion lumineuse et par la concentration des elëments en solution dans i'eau aspirés dans la flamme, a été mesurée pour plusieurs atomes. Un modèle thēorique pour le processus d'accroissement de l'ionisation par excitation laser a êté développé et comparé aux résultats expérimentaux. Cette comparaison montre l'importance des niveaux d'énergie qui ne sont pas impliqués directement dans les excitations lasers. L'accord entre théorie et expérience est satisfaisant. Quelques explications possibles sont proposées et discutées à propos des points de désaccord.

\begin{abstract}
Opto-galvanic or laser-enhanced ionization (LEI) spectroscopy has been performed on trace elements in a flame using one- and two-step laser excitations. The sensitivity, defined as the LEI signal divided by the laser pulse energy and the concentration of the trace element in the water solution aspirated into the flame, has been measured for a number of elements. A theoretical model for the LEI process has been developed and tested. The importance of enerny levels, not involved in the laser transitions, is emphasized. The agreement between theory and experiment is satisfactory. Possible reasons for discrepancies which arise are discussed.
\end{abstract}

The increase of ionization rate due to laser irradiation of atoms in a flame causes a charge increase, which can be measured by applying a voltage over the region of interaction. This is the basic principle of optogalvanic spectroscopy (OGS) or laserenhanced jonization spectroscopy (LEI). Laser-enhanced ionization signals have been observed for a wide range of elements studied in flames and discharges $/ 1 /$.

During recent years LEI spectroscopy has established itself as a powerful technique for trace element analys is in flames /2/. Many elements have been investigated with this technique using both one- and two-step laser excitations. Detection limits of sub-parts per billion (sub-ppb) have been reached /2/, without sacrificing the convenience of the analytical flame as an atomizer. A study of the various processes that contribute to the optogalvanic effect has been undertaken by Turk et al. $/ 3 /$. Here the theoretical emphasis was on the very simple three-level model for the LEI signal.

In our laboratory we have performed LEI experiments in flames using one- and two-step laser excitations. Figure 1 shows schematically our experimental set-up. Two-step excitation was achieved by using two separate tunable dye lasers pumped by the same laser. An air-acetylene flame at atmospheric pressure utilizing a single-slot burner was used. A water solution with the analyte element is aspirated into the flame. The temperature of the hottest part of the flame is assumed to be approximately $2200 \mathrm{~K}$. The laser-induced charge is collected by means of a pair of steel plates kept at a negative voltage of $\approx 2000 \mathrm{~V}$ with respect to the burner head. The laser induced charge increase is collected and electronically analysed.

For the one-step laser excitation experiment a Chromatix CMX 4 flash-lamp pumped dye 


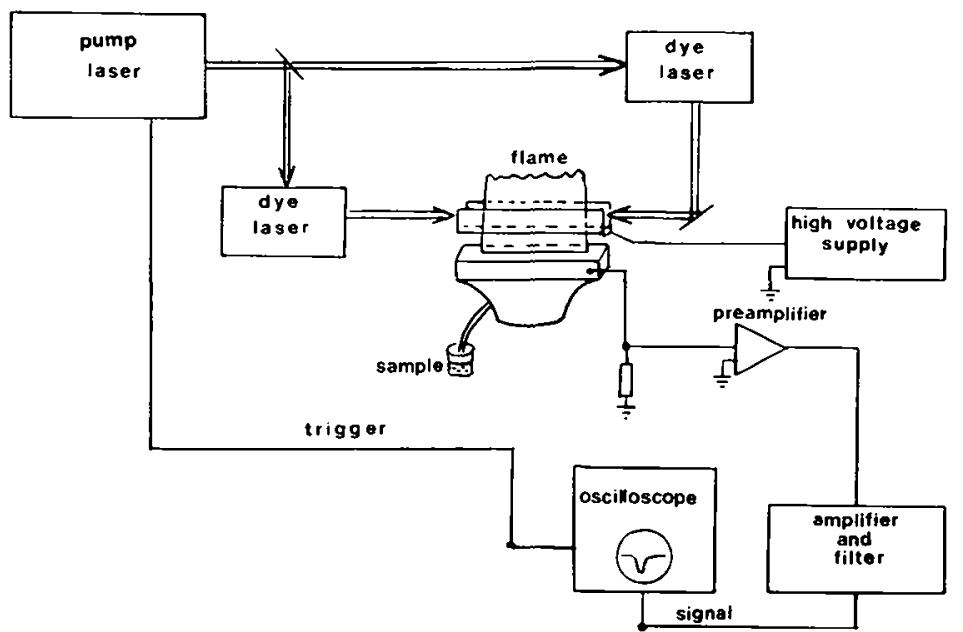

Eigure 1. Block diagrom of the experimental set up for two-step laser excitation optogalvanic spectroscopy in flames.

laser was used. The results from these measurements, are given in table I. The laser pulse energy and the duration of the pulse were recorded for each transition and the optogalvanic signal together with its duration was measured. The sensitivity was then calculated - apart from sodium - as a charge increases per laser pulse energy $\left(E_{L}\right)$ and concentration of the anatyte atom $\left(c_{a}\right)$

$$
S_{1}=\frac{S}{E_{L} C_{a}}
$$

As can be seen from the table the sensitivities between different elements vary several orders of magnitude. In order to reproduce and understand these variations we have studied the effect theoretically.

Several processes can contribute to the optogalvanic signal. In most cases, however, we believe that the dominating process is the increased ionization of the laserexcited analyte atoms. We have developed a model for this process and derived general formulas for the enhancement of the ionization rate at one- and two-step laser excitation. The results obtained in this way are compared with the experimentally determined enhancements.

Our model is based upon the assumptions that the atomic energy levels are populated according to the Boltzmann distribution law and that the collision excitation rates follow the condition of detailed balance. These two conditions can be expressed as:

$$
\frac{n_{i}}{n_{j}}=\frac{k_{j i}}{k_{i j}}=\frac{g_{j}}{g_{j}} \exp \frac{E_{j}-E_{i}}{k T}
$$

where $n_{i}\left(n_{j}\right) ; E_{j}\left(E_{j}\right)$ and $g_{j}\left(g_{j}\right)$ are the population, energy and degeneracy, respective$l y$, of level $i(j)$ and $k_{i j}$ is the collision excitation rate from level $i$ to $j$.

In the simplest model we consider three energy levels, as shown in Fig. 2 . Here the laser transition takes place between the levels 1 and 2 and level $i$ represents a highlying level from which the ionization takes place. We assume that collision excitation rates from level 1 can be neglected and furthermore we neglect spontaneous emission. We are then left with the processes, shown in the figure. Assuming thermal equilibrium, it is easy to solve the corresponding rate equations, and we get the following increase of the population of level $i$, compared to thermal equilibrium without laser excitation, 
Figure 2. Processes considered in the treatment of the three level system.

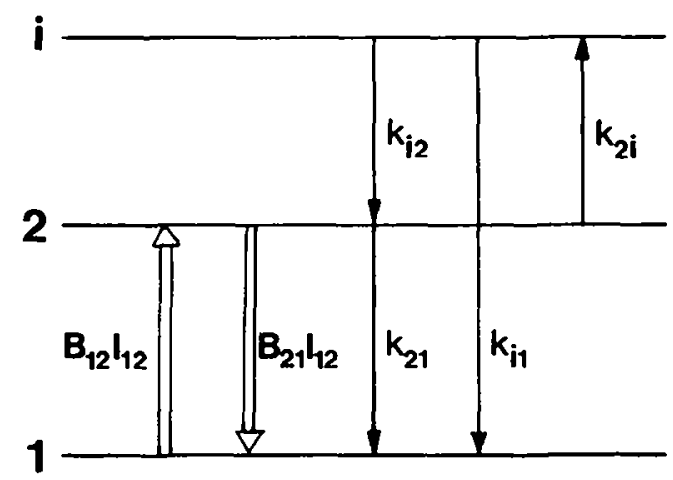

$$
\frac{\left(n_{i}\right) L E}{\left(n_{i}\right)_{T H}}=\frac{B_{12} I 12 \frac{g_{1}}{g_{2}} \exp \frac{E_{2}-E_{1}}{k T}}{\left[k_{21}+\left(1+\frac{g_{1}}{g_{2}}\right) B_{12} I_{12}\right]\left(1+\frac{k_{i 1}}{k_{i 2}}\right)}
$$

Here, $B_{12}$ is the Einste in coefficient for absorption and $I_{12}$ is the spectral irradiation of the laser light. The population of all high-lying levels is increased by essentially the same factor, as long as the collision rates $k_{i}$ and $k_{i 2}$ stay constant. Since the main contribution to the ionization rate is assumed to come from these high-lying levels, Eq (3) is also an approximate expression for the enhancement of the ionization rate, $\frac{\mathrm{dn}_{i}}{\mathrm{dt}}$, in this model,

$$
\frac{\left(\frac{d n_{i o n}}{d t}\right) L E}{\left(\frac{d n_{i o n}}{d t}\right)_{T H}}=\frac{B_{12} I 12 \frac{g_{1}}{g_{2}} \exp \frac{E_{2}-E_{1}}{k T}}{\left[k_{21}+\left(1+\frac{g_{1}}{g_{2}}\right) B_{12} I_{12}\right]\left(1+\frac{k_{i 1}}{k_{i 2}}\right)}
$$

where $k_{i 1}$ and $k_{i 2}$ are the collision deexcitation rates from a level close to the ionization level to the two laser levels.

The three-level system represents an oversimplification of the real system, since no other levels than those directly involved in the process have been considered. In order to make the model more realistic we consider a four-level system with an intermediate level (I) as indicated in Fig. 3. With the same assumptions as before and

Figure 3. Processes considered in the treatment of the three level system with intermediate levels (I).

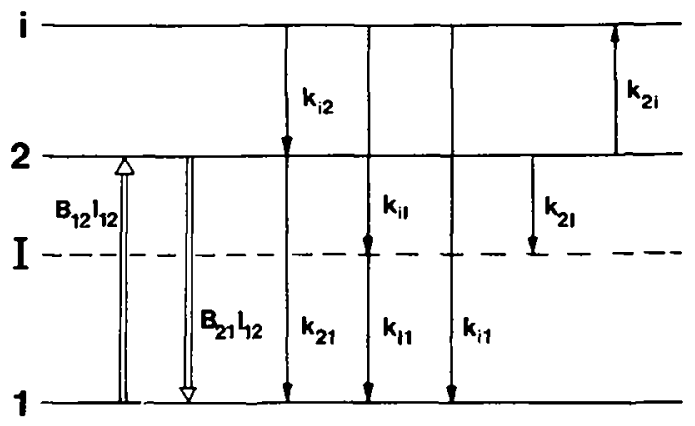


with analogous notations, we find that the enhancement of the ionization rate becomes in this case

$$
\frac{\left(\frac{d n_{i o n}}{d t}\right)_{L E}}{\left(\frac{d n_{i o n}}{d t}\right)_{T H}}=\frac{B_{12} I_{12} \frac{g_{1}}{g_{2}} \exp \frac{E_{2}-E_{1}}{k T}}{\left[k_{21}+k_{2 I}+\left(1+\frac{g_{1}}{g_{2}}+\frac{k_{2 I}}{k_{I 1}}\right) B_{12} I_{12}\right]\left(1+\frac{k_{i 1}+k_{i I}}{k_{i 2}}\right)}
$$

This differs from the expression for the three-level system (4) by the appearance of the $k_{2 I}$ and $k_{i I}$ factors in the denominator. If we let $k_{2}$ and $k_{i}$ represent the total collision rates to these levels then it can be shown that the same formula is approximately valid for a system with several intermediate levels. Since the number of intermediate levels in some cases can be quite large, we see that the reduction of the enhancement factor due to these levels can be appreciable.

The model considered here can easily be extended to the two-step process, in which case we consider the energy-level system shown in Fiy. 4. Assuming that the first

Fig. 4. Energy levels involved in the treatment of the two-step laserexcitation process. $I^{\prime}$ and $I^{\prime \prime}$ represent intermediate levels between the levels involved in the laserinduced transitions.
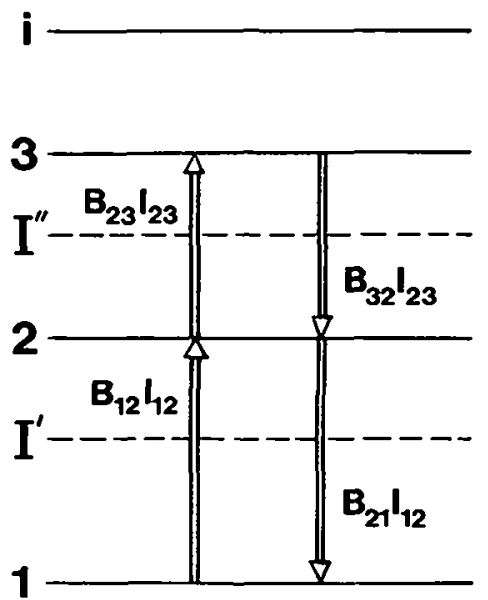

laser transition $(1 \leftrightarrow 2)$ is saturated and that the second transition $(2 \leftrightarrow 3)$ is far from saturation, we find that the total enhancement of the ionization rate due to the two laser steps is

$$
\frac{\left(\frac{d n_{i o n}}{d t}\right) L E}{\left(\frac{d n_{i o n}}{d t}\right)_{T H}}=\frac{B_{23} I_{23} \frac{g_{1}}{g_{3}} \exp \frac{E_{3}-E_{1}}{k T}}{\left(k_{31^{+}}+k_{32}+k_{3 I^{\prime}}+k_{3 I^{\prime \prime}}\right)\left(1+\frac{g_{1}}{g_{2}}+\frac{2 I^{\prime}}{k_{I 1}}\right)\left(1+\frac{k_{i 1}+k_{i 2}+k_{i I^{\prime}+k_{i I^{\prime \prime}}}}{k_{i 3}}\right)}
$$

As before, summations can be performed over the intermediate levels I' and I". As the number of intermediate levels can be particularly large for the second step (I"), we see that it is even more important to take these levels into account in the two-step process.

So far we have assumed that there are no levels below the lower laser level and that all levels are well separated from the two laser levels. In our calculations, however, we take all possible levels into account. 
In order to apply the general formulae it is, in principle, necessary to know all the collision transition rates involved as well as the thermal ionization rates. Lacking such knowledge we have to make a few assumptions. The transition rates from level $i$ are assumed to be proportional to the degeneracy of the final state, i.e.

$$
k_{i j} \propto g_{j}
$$

The transition rate from level 2 (the quenching rate) is assumed to be $7 \mathrm{GHz}$ - based on saturation measurements of the quenching rate for sodium. The thermal ionization rate is assumed to be $2 \cdot 10^{12} \mathrm{e}^{-\frac{E_{I}}{K T}} \mathrm{~Hz}$ based on the available values for ionization rates of alkalies $/ 4 \%$. These values are measured in a $\mathrm{H}_{2} / \mathrm{O}_{2} / \mathrm{N}_{2}$ flame at the temperature of $2250 \mathrm{~K}$ which is close to the value used in our calculations.

With these additional assumptions we can now calculate the ionization rate. The signal also depends on atomization and other flame conditions. The sensitivity (1) can then be expressed as

$$
\Sigma=Q \frac{B_{a}}{M_{a}}\left(\frac{n_{i o n}}{n_{\text {tot }}}\right) \text { LE }
$$

where $\beta_{a}$ is the degree of atomization, $M_{\alpha}$ the atomic mass of the analyte atom and $Q$ is a constant for a specific experimental set-up. The sensitivities calculated in this way are shown in table 1 .

Table 1. Optogalvanic spectroscopy by one-step laser excitation. Experimental and

\begin{tabular}{|c|c|c|c|c|c|c|}
\hline Element & $\lambda(n m)$ & $\mathrm{B}_{\mathrm{a}}$ & $E_{I}\left(\mathrm{~cm}^{-1}\right)$ & $\begin{array}{c}\Sigma_{\exp } \\
(\mathrm{fC} / \mu \mathrm{Jppm})\end{array}$ & $\begin{array}{l}\Sigma_{\text {theory }} \\
(\mathrm{fC} / \mu \mathrm{Jppm})\end{array}$ & $\frac{\Sigma_{\text {th }}}{\varepsilon_{\exp }}$ \\
\hline $\begin{array}{l}\mathrm{Na}^{*} \\
\mathrm{Mg} \\
\mathrm{Cr} \\
\mathrm{Mn} \\
\mathrm{Fe} \\
\mathrm{Ni} \\
\mathrm{Cu} \\
\mathrm{Ga} \\
\mathrm{In} \\
\mathrm{Tl} \\
\mathrm{Bi}\end{array}$ & $\begin{array}{l}589.0 \\
294.2 \\
301.76 \\
204.04 \\
302.06 \\
300.25 \\
296.12 \\
294.36 \\
303.94 \\
291.83 \\
306.77\end{array}$ & $\begin{array}{l}1 \\
0.6 \\
0.065 \\
0.6 \\
0.4 \\
1 \\
1 \\
0.2 \\
0.6 \\
0.5 \\
0.2\end{array}$ & $\begin{array}{l}41450 \\
61071 \\
54670 \\
59960 \\
63700 \\
61579 \\
62317 \\
48388 \\
46680 \\
49264 \\
58970\end{array}$ & $\begin{array}{c}330000 \\
0.22 \\
1.1 \\
2.2 \\
0.87 \\
0.25 \\
0.06 \\
108 \\
2200 \\
370 \\
6.5\end{array}$ & $\begin{array}{c}1800000 \\
0.004 \\
23 \\
0.35 \\
0.12 \\
3.4 \\
0.97 \\
21000 \\
40000 \\
320 \\
10\end{array}$ & $\begin{array}{l}5.5 \\
0.019 \\
21 \\
0.16 \\
0.14 \\
14 \\
16 \\
190 \\
18 \\
0.87 \\
1.6\end{array}$ \\
\hline
\end{tabular}
theoretical sensitivities

*In this measurement the transition was saturated and the signal/ppm was used for comparison without dividing with laser power since the signal was not linear to laser energy.

We can see from this table that the theoretical sensitivities are in good agreement with the trends in the experimental results. In view of the fact that we lack experimental information about the collision transition rates, this is a satisfactory result and indicates that the model is in most cases based on realistic assumptions. For some elements, another ionization channel, such as the formation of a metal oxide as an intermediate step may be of importance. This may explain the relatively high sensitivity found experimentally for some elements. In a few cases, particularly for gallium, the calculated sensitivity is remarkably high compared to the experimental one. The reason for this is not entirely understood at present. 
Table 2. Sodium: Experimental and theoretical enhancements $x$ of the optogalvanic signal by the second-step laser excitation as compared to one-step signa?. First step transition $3 \mathrm{~s}-3 p_{3 / 2} \lambda_{1}=589 \mathrm{~nm}$.

\begin{tabular}{|c|c|c|c|c|c|c|c|}
\hline Transition & $\begin{array}{c}\lambda_{2} \\
(\mathrm{~nm})\end{array}$ & $x_{\exp }$ & $x_{\text {theory }}$ & Transition & $\begin{array}{c}\lambda_{2} \\
(\mathrm{~nm})\end{array}$ & $x_{\exp }$ & $x_{\text {theory }}$ \\
\hline $3 p_{3 / 2^{-5 s}}$ & 616.1 & 500 & 450 & $3 p_{3 / 2^{-4 d}}$ & 568.8 & 1600 & 2850 \\
\hline $3 \mathrm{p}_{1 / 2^{-5 s}}$ & 615.4 & 120 & 190 & $3 p_{1 / 2^{-4 d}}$ & 568.3 & 1100 & 1500 \\
\hline $3 p_{3 / 2^{-6 s}}$ & 515.3 & 145 & 110 & $3 p_{3 / 2^{-5 d}}$ & 498.3 & 656 & 689 \\
\hline $3 p_{1 / 2^{-6 s}}$ & 514.9 & 55 & 48 & $3 p_{1 / 2^{-5 d}}$ & 497.9 & 328 & 317 \\
\hline $3 p_{3 / 2^{-7 s}}$ & 475.2 & 72 & 66 & $3 p_{3 / 2^{-6 d}}$ & 466.9 & 622 & 467 \\
\hline $3 p_{1 / 2^{-7 s}}$ & 474.8 & 36 & 34 & $3 p_{1 / 2}-6 d$ & 466.5 & 327 & 173 \\
\hline $3 p_{3 / 2^{-8 s}}$ & 454.5 & 80 & 35 & $3 p_{3 / 2^{-7 d}}$ & 449.8 & 400 & 178 \\
\hline $3 p_{1 / 2^{-8 s}}$ & 454.2 & 26 & 17 & $3 p_{1 / 2}-7 d$ & 449.4 & 167 & 89 \\
\hline $3 p_{3 / 2^{-9 s}}$ & 442.3 & 20 & 15 & $3 p_{3 / 2^{-8 d}}$ & 439.3 & 280 & 46 \\
\hline $3 p_{1 / 2^{-9 s}}$ & 442.0 & 11 & 13 & $3 p_{1 / 2^{-8 d}}$ & 439.0 & 140 & 20 \\
\hline
\end{tabular}

Two-step LEI experiments have been performed for sodium. The sensitivity can here be expressed in a similar way as in the one-step process. The calculated and measured increase in the sensitivity is given in table 2. The agreement between theory and experiment is quite good, which is partly due to the fact that in taking the ratio of two sensitivities the uncertainties in many parameters are eliminated. As mentioned previously, the inclusion of intermediate states in the model is very crucial in this case and a simple four-level model would strongly overestimate the enhancement.

Recently we have also performed LEI-experiments on several elements using Excimer pumped dye lasers. The detection limits which were obtained are given in table 3 .

Table 3. Experimental limits of detection (in $\mathrm{ng} / \mathrm{mT}$ ). Detection limits which are given in brackets indicate that the used wavelength was not optimal for LEI.

\begin{tabular}{|c|c|c|}
\hline Element & $\lambda[\mathrm{nm}]$ & Det.limit $[\mathrm{ng} / \mathrm{m}]]$ \\
\hline $\mathrm{Bi}$ & 302.460 & $(30)$ \\
$\mathrm{Co}$ & 304.400 & $(4)$ \\
$\mathrm{Cr}$ & 301.490 & $(24)$ \\
$\mathrm{Fe}$ & 302.060 & 0.08 \\
$\mathrm{Ga}$ & 294.364 & 0.04 \\
$\mathrm{In}$ & 303.936 & 0.017 \\
$\mathrm{Mg}$ & 285.213 & 0.003 \\
$\mathrm{Mn}$ & 292.557 & $(2)$ \\
$\mathrm{Na}$ & 285.250 & $<0.001$ \\
$\mathrm{Ni}$ & 301.200 & 1 \\
$\mathrm{~Pb}$ & 287.332 & $(2)$ \\
$\mathrm{Sn}$ & 286.333 & $(15)$ \\
$\mathrm{Tl}$ & 291.820 & 0.015 \\
$\mathrm{i}$ & & 0.003 \\
$\mathrm{~L} *$ & $670.8 ; 610.4$ & 0.003 \\
\hline
\end{tabular}

* two-step laser excitation LEI measurement 
Here, no comparison with theory has yet been made. Due to the short laser pulse, it is uncertain whether the steady-state equations, on which our model is based, are applicable.

\section{References:}

1. Goldsmith J.E.M. and Lawler J.E., Contemp. Phys. 22 (1981) 235

2. Travis J.C., Turk G.C., Green R.B., Anal. Chem. T1982) 1006 A

3. Travis J.C., Schenck P.K. and Turk G.C., Mallard W.G., Anal. Chem. 51 (1979) 1516

4. Miller W.J., 15th Symposium (Int) on Combustion (1973) 307 